\title{
Long-Term Capital Gains Tax Strategies: Correlated Protective Put Strategy
}

John R. Aulerich, (E-Mail: aulericj@uww.edu), University of Wisconsin-Whitewater James Molloy, University of Wisconsin-Whitewater

\begin{abstract}
A reduction in the long-term capital gains tax rate provides investors with new strategies to minimize taxes and protect investment gains. One such opportunity exists when an investor decides to sell a profitable stock with a holding period of less than one-year, resulting in shortterm ordinary taxes. The investor would find it more beneficial to sell the stock after one-year lapses, resulting in lower long-term capital gain taxes, although the longer holding period exposes the investor to the uncertainty of stock price movement. A strategy to extend the holding period without excess risk would be to use the protective put option strategy, sometimes referred to as "investment insurance". The strategy involves the purchase of a put option to protect against the possible decline in the stock price, to take advantage of the lower long-term capital gains tax rate, and to preserve the upside potential of the stock. Pursuant to IRS Publication 550, the IRS does not allow the use of a protective put to extend the holding period on the same security considered for sale. Since the IRS does not allow a direct protective put hedge, this study will explore an alternative strategy involving the purchase of a put on a highly correlated investment to extend the holding period to recognize lower capital gains tax rates. The paper presents example situations when an investor benefits from utilizing the correlated protective put option strategy.
\end{abstract}

\section{Introduction}

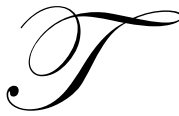

he Jobs and Growth Tax Relief Reconciliation Act of 2003 reduces the long-term capital gains tax rate to provide investors with opportunities to minimize taxes and protect investment gains. The Act can be applied when an investor must choose whether to sell a profitable stock with less than a oneyear holding period at what he/she believes is a selling opportunity, realizing the short-term capital gains tax rate (assuming the profit would not be offset by other capital losses) Act Sec.301(a)(1) and Act Sec.301(a)(2)(A) amended Code Sec.1(h)(1)(B) and Sec.1(h)(1)(C), or he/she waits at least one-year before selling, realizing the lower, long-term capital gains tax rate Sec.1(h)(1)(B) and Sec.1(h)(1)(C). However, he/she risks a decline in the price of the stock from the point of the decision to the completion of the one-year holding period. The protective put option contract strategy, called "investment insurance", protects against a decline in the stock price by purchasing a put option to benefit from the lower long-term capital gains tax rate and to preserve the upside potential of the stock. As stated in publication 550 by the IRS, an investor cannot use a protective put on the same investment considered for sale in order to extend the holding period of the long position. ${ }^{1}$ However, the strategy may be legally modified if an investor purchases a protective put on an investment with high correlation in the returns to the investment considered for sale. The correlated protective put strategy (CPPS) will allow for continued up-side potential on the investor's current long position while limiting the downside risk exposure and allowing for tax reductions with the longer holding period.

This paper will address the fundamentals of the CPPS option contracts and proceed to explore the current advantages of this strategy. The analysis compares the total after-tax value of an investment portfolio utilizing the CPPS approach to the total after-tax value of an investment portfolio not using the CPPS approach; that is, just selling the investment prior to a one-year holding period and reinvesting the proceeds in a safe interest-bearing account.

\footnotetext{
${ }^{1}$ IRS Publication 550 "Investment Income and Expenses (Including Capital Gains and Losses)" page 54, www.irs.gov.
} 


\section{Straight Protective Put Strategy}

A put option is a contract that allows the put purchaser to sell the underlying asset at a specified price by a specified date. ${ }^{2}$ The specified price in the contract is referred to as the strike price or exercise price, and the specified date is referred to as the exercise date. Puts on individual stocks are sold in 100 share lots; as a result, one put contract controls 100 shares of the underlying stock. For example, an investor holds XYZ stock currently trading at $\$ 40$ per share and wants to protect the price by utilizing a protective put strategy. He/She would purchase a put option and pay the premium (the price of the put option contract and fees associated with the purchase) to receive the right to sell $\mathrm{XYZ}$ at the strike price by the exercise date. The premium paid for the put option represents the "insurance" an investor pays to protect the price of his/her investment. Assuming the strike price of the option is $\$ 40$ per share and the put contract has a premium of $\$ 3$, the payoff of the put option at expiration, or when exercised, is shown in Chart 1.

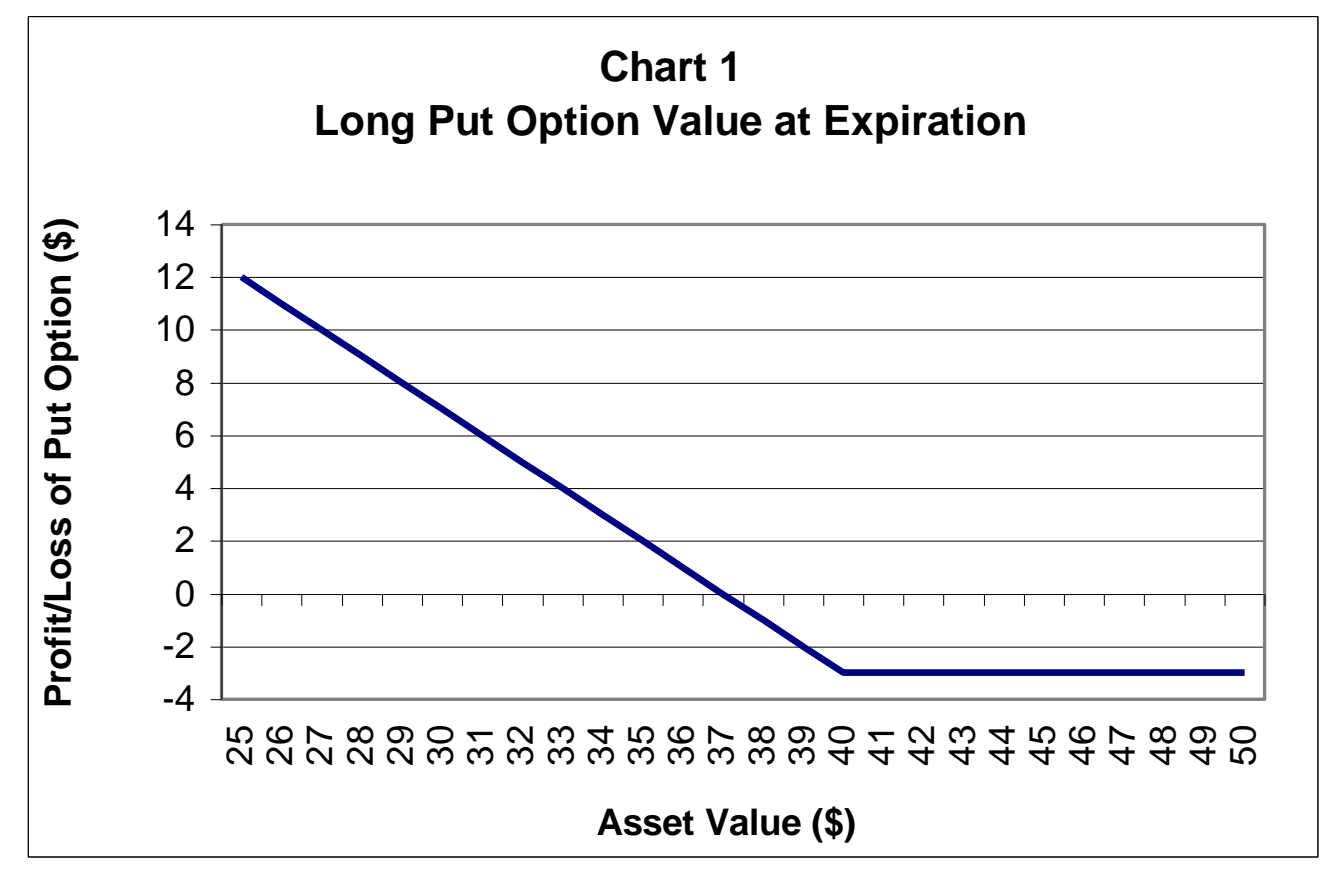

A value assessment of the investor's position in XYZ shows the benefit of using a protective put option as an investment strategy. The payoff for the investment's long stock position, the protective put position, and the combined value are shown in Chart 2.

Using a protective put option is like having price insurance on the long position in XYZ. Shown above, the combined portfolio value indicates that if the price of XYZ decreases over the life of the put option, the investor only loses the premium he/she paid for the put option, because the investor can sell his/her shares for the strike price of $\$ 40$ per share. If the price of XYZ increases over the life of the put option, the investor can sell the shares for the increased market price and allow the put option to expire unexercised. In both cases, the put premium represents the cost of "insurance" to the investor.

\footnotetext{
${ }^{2}$ We assume the use of an American put option, which can be exercised at any time during the life of the option. Although, with the strategy presented in this paper, a European put option would work because we are only using the option to extend the sale date of the correlated asset.
} 


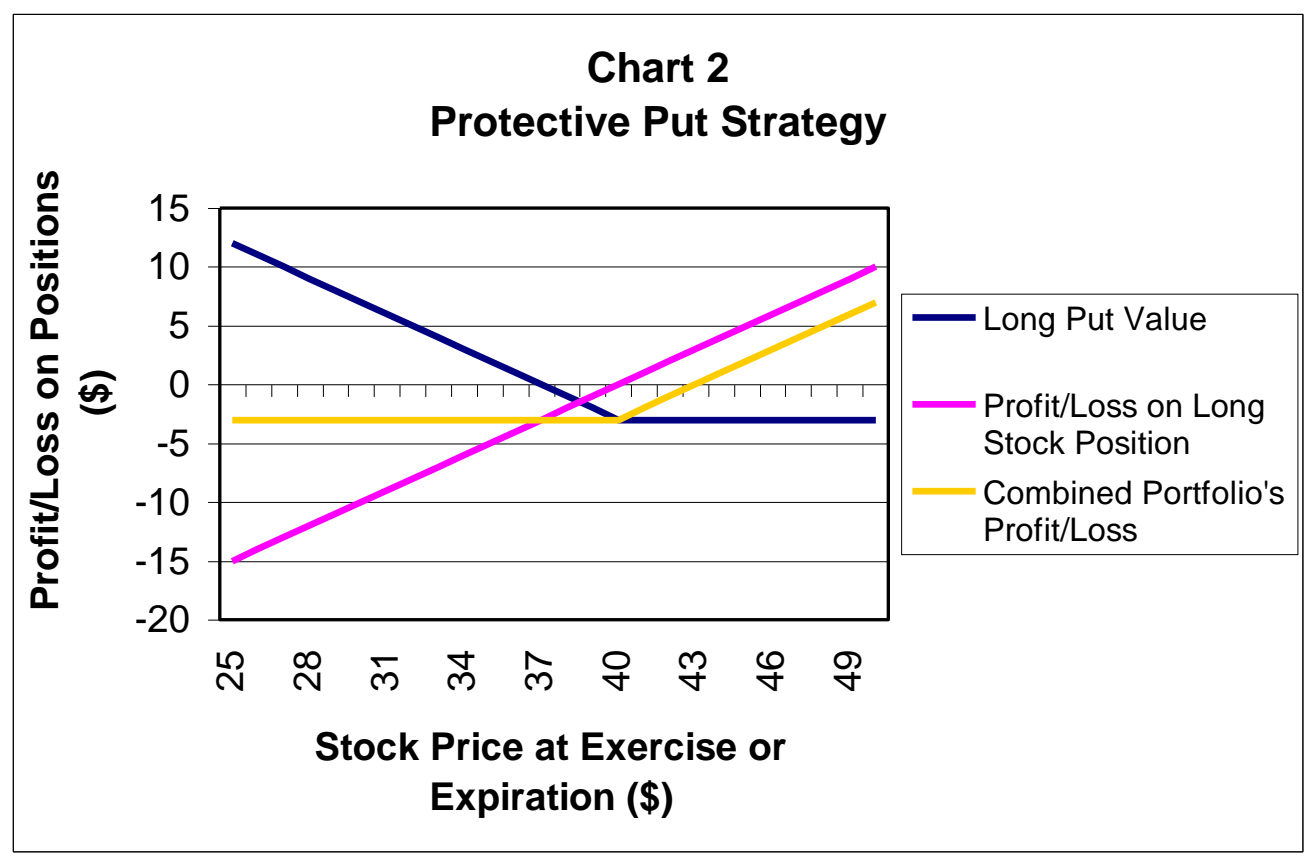

A put option is characterized as in-the-money, at-the-money, or out-of-the-money. The characterizations refer to the price of the underlying stock relative to the strike price of the put option. If the put option is in-themoney, the current stock price is lower than the strike price. If the put option is at-the-money, the current stock price is equal to the strike price. If the put option is out-of-the-money, the current stock price is above the strike price. An investor would exercise the put option if the current stock price is lower than the strike price of the put option (in-the-money). If the current stock price is higher than the strike price, then the investor would let the put option expire unexercised (out-of-the-money).

\section{Irs Publication 550}

The IRS determined an investor attempting to extend the holding period of an investment by purchasing a put option on that investment, would be taking unfair advantage of the tax structure. As a result, IRS publication 550 states if an investor purchases a put option on an existing long position, he/she is in essence, resetting the holding period for the investment to start on the purchase date of the corresponding put option. An investor must bear the risk of a decline in stock value when extending the holding period of an investment past one-year, no direct put hedges are allowed to extend this holding period. An alternative choice to bearing the risk would be the CPPS hedge. The CPPS will work best when finding a highly correlated stock to the long position. The CPPS is acceptable by standards set in the IRS publication 550 and can be used to extend the longer holding period, recognizing lower capital gains tax rates.

\section{Methodology}

This study outlines an investment/tax strategy (CPPS) to conserve paper profit, extend the holding period to realize a lower long-term capital gains tax rate, and still allow for upside potential and limiting downside risk. To obtain the benefit of the lower, long-term capital gains tax rates, this strategy requires the investor to hold the long position in the stock for at least a year Sec.1(h)(1)(B) and Sec.1(h)(1)(C). To demonstrate CPPS benefits, an investment portfolio utilizing the strategy to extend the holding period is compared to an investment portfolio that does not attempting to extend the holding period and merely sells the investment before a one-year holding period lapses and reinvests the proceeds for the remainder of the year in an interest-bearing account. An investor utilizing CPPS can purchase an in- or at-the-money put option on an investment highly correlated to the current long 
investment position, and at the end of the year-long holding period, the combined correlated put and long stock profit, if realized, would be taxed at the favorable long-term capital gains tax rate. In theory, if the stock price of the original long holding position declines, the correlated put option should increase in value, and an investor would exercise or sell the put option for a gain, offsetting the decline in the long position. Thus, the investor recognizes a short-term gain on the put option, and if a profit still exists on the long position, it will be taxed at a lower capital gains tax rate. If the stock price of the long position increases, the investor will let the correlated put option expire worthless, assuming it is not valuable, and sell the stock on the open market for a greater gain at a lower capital gains tax rate. If, however, the CPPS to extend the holding period is not utilized by an investor, taxes would then be paid at the investor's ordinary income tax rate on the profit generated by the sale and any earned interest Sec.1(i)(1) and Sec.1(i)(2).

When the two investment portfolios are compared at the end of a twelve-month holding period on an aftertax basis, assuming a perfectly CPPS will either result in a higher value for the CPPS portfolio, or a value slightly lower as a result of the premium paid for the purchase of the correlated put option "insurance". The remainder of the paper will first demonstrate the model theoretical examples with perfectly correlated investments (put and long position) and generate the values of the theoretical portfolios, and then the second section of this paper will use actual investments in the marketplace which are not perfectly correlated investments and compare the resulting portfolio values.

\section{Theoretical Results Of The Correlated Protective Put Strategy}

\section{Sufficient Gains on Investment to Cover Cost of Put}

Assume an investor owns a security, which created paper profit over part of a year holding period, but he/she believes the security value will fall during the remainder of the year, reducing or eliminating the paper profit. The investor wants to take the gain, but at the same time he/she does not want to pay the higher taxes for the shortterm holding period. He/She could use a CPPS to extend the holding period of the investment and protect the profit on the long position. In order to create a theoretically perfect CPPS and have the ability to recognize a lower tax rate on capital gains, the investor would have to find an investment with perfectly correlated returns to the long position (virtually impossible), and the correlated security must have put options available.

If an investor can find a perfectly correlated investment, then two potential results are possible depending on the size of the capital gain and the cost of the put option to protect the investment. The first theoretical example using perfectly CPPS to extend the holding period to longer than one-year, and recognizing a lower long-term capital gains tax rate, produces a gain sufficient to offset the cost of purchasing the put option. The outcome depends on the tax rate of the investor, the gain on the long investment, and the cost of the put option. Chart 3 below shows the example of the theoretical results after a one-year holding period when the investor made an investment on January 2, 2003, and has a paper gain of $\$ 2,500.00$ on October 28, 2003. The investment was purchased at $\$ 15.00$ and has a market price of $\$ 40.00$ on October 28,2003 . He/She can purchase a theoretical perfectly correlated put option for $\$ 3.50$ on October 28,2003 , on margin at a $5 \%$ rate, with a strike price of $\$ 45$, a commission cost of \$12.00, and expiration date of January 16, 2004.

The perfectly correlated put option is purchased with margin dollars at a 5\% rate of interest until January 3 , 2004 , at which time, the loan is repaid when the underlying position is liquidated. ${ }^{3}$ This is a self-financing strategy that an investor could use when purchasing the perfectly correlated put option. ${ }^{4}$ The interest on the margin loan is $\$ 3.29$, for a total cost of $\$ 365.29$ for the put option.

Chart 3 shows how the investor fares with this theoretical perfectly CPPS if he/she was in the $10 \%, 15 \%$, $25 \%, 28 \%, 33 \%$ or $35 \%$ ordinary income tax bracket Sec.1(i)(1) and $\operatorname{Sec}(1)(i)(2)$. Shown in Chart 3 is the difference between the after-tax value of the investment portfolio utilizing the perfectly CPPS and the after-tax value

\footnotetext{
${ }^{3}$ The margin rate of $5 \%$ is taken from the rates quoted at www.ameritrade.com website on October 26, 2003.

${ }^{4}$ If the investor does not need to use margin capital to purchase the put option, the return (or cost) from the strategy would be greater (lower), thus resulting in a higher portfolio value.
} 
of the investment not utilizing the CPPS when the investor sold the stock on October 28, 2003, with the proceeds reinvested in an account earning the margin rate of return. ${ }^{5}$

Table 1 shows the after-tax difference in value between the two portfolios when the price of the stock falls below the $\$ 15.00$ per share. If this occurs, the perfectly correlated put option would be exercised or sold for a gain and taxed at the ordinary income tax rate, and the investor now has a loss on the long investment on January 3, 2004. If the value in Table 1 is positive, the perfectly correlated protective put option strategy is beneficial to the investor for the amount shown, and if the value is negative, the value represents the price paid by the investor for the "insurance" he/she purchased with the perfectly correlated put option. The results shown in Table 1 for all ordinary income tax rates indicate that an investor is better off utilizing the protective put strategy because the reduction in the capital gains tax more than offsets the cost of purchasing the theoretical perfectly correlated protective put. In addition, the investor maintains the up-side potential in the underlying asset for the remainder of the one-year holding period.

Also shown in Chart 3, if the price of the stock increases above the strike price for all the ordinary income tax brackets, the investor would allow the option to expire and sell the underlying stock at a higher profit than he/she would have realized if the sale occurred on October 28, 2003. In Table 1, the values are decreasing as the ordinary income tax rate is increasing because the gain on the put option is taxed on ordinary income and the gain on the long investment is reduced or lost.

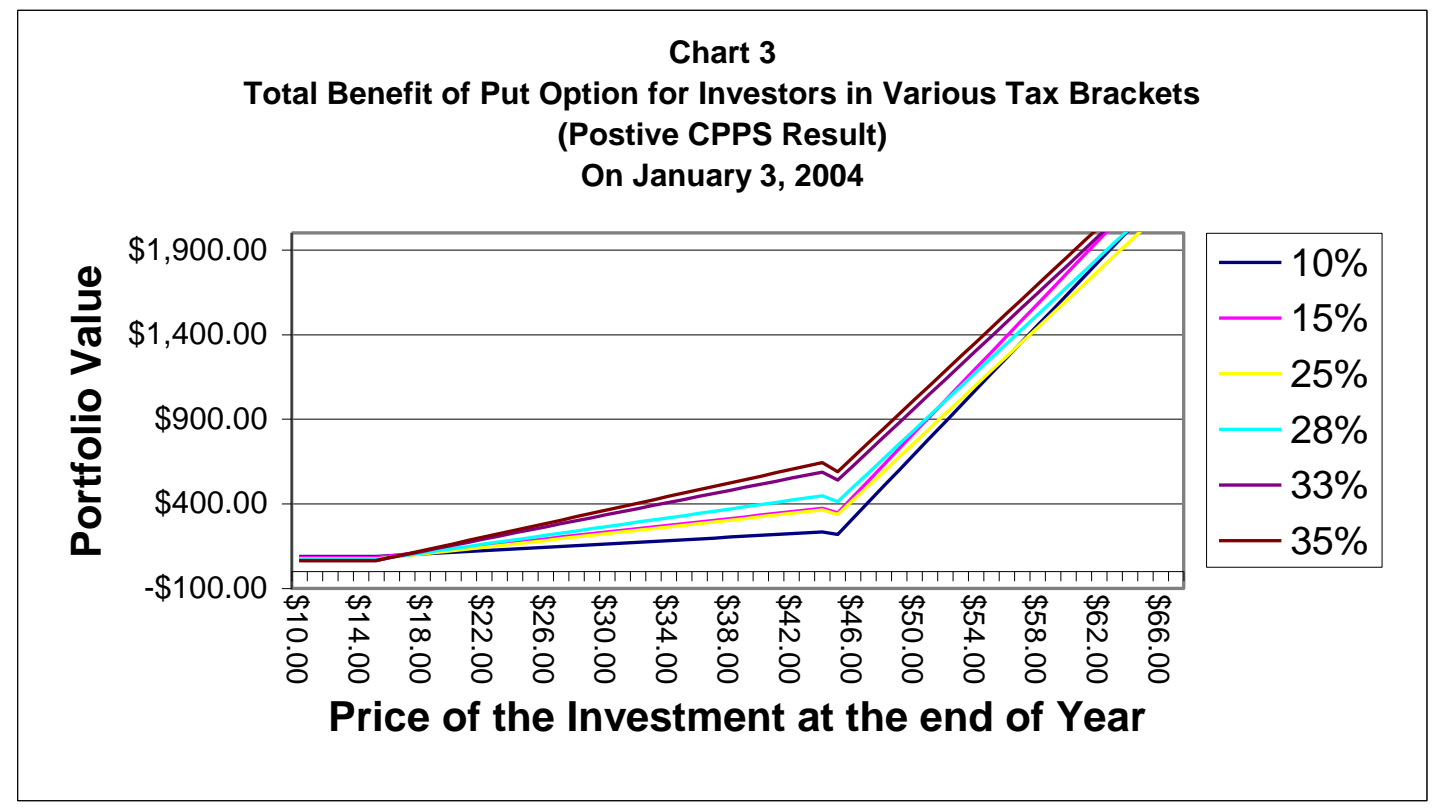

\section{Small Gain on Investment that does not Cover Cost of Put}

Suppose an investor is faced with a situation where he/she has a gain in the price of the stock, but the gain is not large enough for the lower long-term capital gains tax rate to offset the entire cost of the theoretical perfectly correlated put option. The CPPS would still be useful in reducing the effective price of the correlated put option that could be purchased to protect the investor's paper profit while still allowing for upside potential. For example, an investor purchases 100 shares of stock on January 2, 2003, and on October 28, 2003, had a potential paper profit of

\footnotetext{
${ }^{5}$ If the proceeds are placed in a risk-free investment or a money market account, the return of the deposit would be lower, therefore, making the perfectly CPPS even more appealing.
} 
Table 1: Minimum Value of perfectly CPPS (Benefit Example)

\begin{tabular}{|c|c|}
\hline \multicolumn{2}{|c|}{$\begin{array}{l}\text { Value of perfectly correlated protective put } \\
\text { strategy when the price of the investment falls } \\
\text { and the perfectly correlated put gains in value. }\end{array}$} \\
\hline Tax rate & $\begin{array}{r}\text { Benefit if CPPS utilized Option } \\
\text { price at or below } \$ 15.00\end{array}$ \\
\hline $10.00 \%$ & $\$ 88.01$ \\
\hline $15.00 \%$ & $\$ 83.12$ \\
\hline $25.00 \%$ & $\$ 73.34$ \\
\hline $28.00 \%$ & $\$ 70.40$ \\
\hline $30.00 \%$ & $\$ 65.52$ \\
\hline $35.00 \%$ & $\$ 63.56$ \\
\hline
\end{tabular}

$\$ 200.00$. The investment was purchased at $\$ 12.00$ and has a market price of $\$ 14.00$ on October 28,2003 . Since the holding period would be 299 days, if the stock is sold, the profit from sale would be taxed at the ordinary income tax rate of the investor. Demonstrating the perfectly CPPS, the investor purchases an in-, or at-the money put option with an expiration date of January 16,2004 , a strike price of $\$ 15.00$, cost of $\$ 1.50$ per share, for a cost of $\$ 150.00$ plus $\$ 12.00$ commission for a total price of $\$ 162.00$. The perfectly correlated put option is purchased with margin dollars at a 5\% interest rate until January 3, 2004, at which time the loan would be repaid when the underlying position is liquidated. The interest on the margin loan is $\$ 1.49$, for a total cost of $\$ 163.49$ for the put option.

Chart 4 and Table 2 show the results of the theoretical perfectly CPPS if the investor is in the $10 \%, 15 \%$, $25 \%, 28 \%, 33 \%$ or $35 \%$ ordinary income tax bracket. The results represent the difference between the after-tax value of the investment portfolio utilizing the perfectly CPPS and the after-tax value of the investment portfolio not utilizing CPPS with the shares sold on October 28, 2003, and the proceeds reinvested in an account earning the margin rate of interest. Should the price of the stock fall, the perfectly correlated option value would increase and could be exercised or sold on January 3, 2004, offsetting the decline in the long position from October 28, 2003. Table 2 shows the cost of purchasing a theoretical perfectly correlated put option utilizing the CPPS if the stock price on January 3, 2004, is below $\$ 12.00$ per share. Note, in all the ordinary income tax brackets, the cost of purchasing the correlated protective put option $(\$ 163.49)$ is reduced when extending the long investment's holding period to longer than one-year because a the loss on the long investment reduces the effective gain on the put option.

Chart 4 shows the results of an investor using the perfectly CPPS versus selling the investment on October 28, 2003 and investing the proceeds in an interest bearing account. When the stock price declines or does not significantly move the investor would benefit from selling the investment on October 28, 2003, but the CPPS would provide the investor with the opportunity for upside potential for the period from October 28, 2003 through January 3 , 2004. If the long stock price increases, the perfectly correlated put option would be worthless and allowed to expire, and the investor would realize the long-term capital gains tax rate on the long investment. Thus, the investor could encounter a small loss on the perfectly CPPS portfolio if the price of the long position falls, but the small loss incurred is less than the cost of the perfectly correlated put option; or experience a gain if the price of the long position rises from October 28, 2003, to January 3, 2004. 


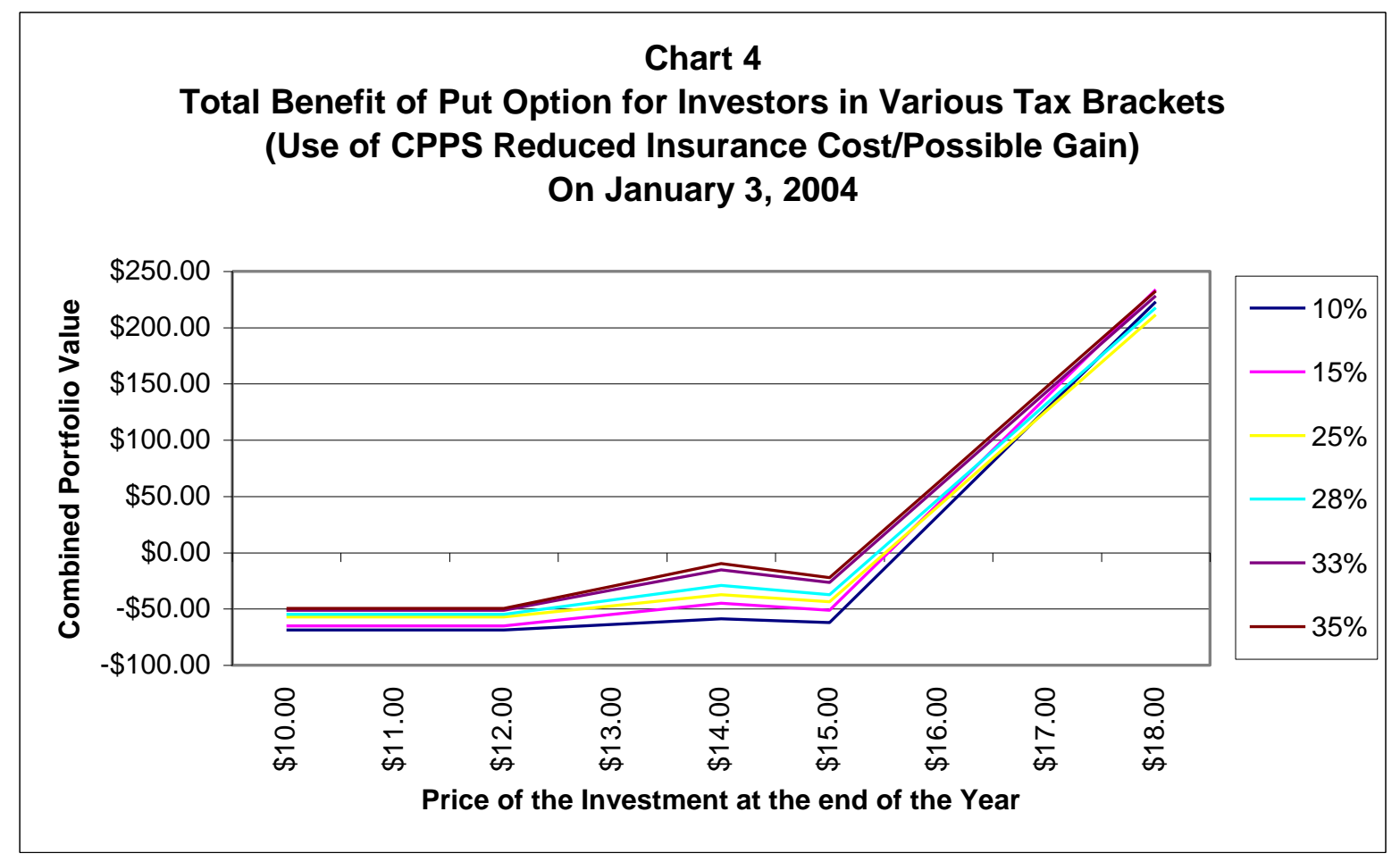

Table 2: Minimum Cost of Perfectly CPPS (Insurance Example)

\begin{tabular}{|c|c|}
\hline \multicolumn{2}{|c|}{$\begin{array}{l}\text { Value of perfectly correlated protective put strategy } \\
\text { when the price of the investment falls and the } \\
\text { perfectly correlated put gains in value. }\end{array}$} \\
\hline Tax rate & $\begin{array}{l}\text { Cost if CPPS utilized } \\
\text { Option price at or below } \$ 12.00\end{array}$ \\
\hline $10.00 \%$ & $-\$ 68.76$ \\
\hline $15.00 \%$ & $-\$ 64.94$ \\
\hline $25.00 \%$ & $-\$ 57.30$ \\
\hline $28.00 \%$ & $-\$ 55.01$ \\
\hline $30.00 \%$ & $-\$ 51.19$ \\
\hline
\end{tabular}

\section{Comments}

Calculating a percentage gain on the investment as a breakeven point is difficult because the option premium or cost of the correlated protective put option will vary as a percentage of the stock price. The premium charged is determined by the market (supply and demand) and not strictly the time to maturity or the stock price relative to the strike price. One of the critical factors in determining the premium on a put option contract is the implied volatility of the underlying asset, and since each asset has different implied volatility with respect to future price movements, the premium will be different. Therefore, it is difficult to assess when the use of a CPPS would result in an overall portfolio gain by utilizing a basic percentage gain as a cut off point. Each analysis must be done on a case-by-case basis.

When comparing Charts 2, 3 and 4, the combined payoff of the portfolio has a hiccup just below strike price in Charts $3 \& 4$ but not in Chart 2. This occurs when the stock price falls below the strike price, and the perfectly correlated put option generates a loss that can be used to offset gain on the long investment position, effectively reducing taxes. This hiccup gets back to normal put protection that declines slightly once the put option becomes profitable. Thus, an investor will be able to offset a portion of the investment gain for tax purposes when the perfectly correlated put option becomes worthless. In essence, an investor can use the "insurance" premium as a tax deduction on his/her capital gain. With the perfectly CPPS, if the long position stock price increases he/she not only gets the added capital gains on his/her investment, but he/she can also deduct the cost of the "insurance" that locked in the capital gain. The declining protection occurs since the put gain is taxed at ordinary income rates while any gain on the long position is taxed at the long-term capital gains rate. 
One could not argue an arbitrage opportunity would be available in the risk-free profit described in the Sufficient Gains on Investment to Cover Cost of Put theoretical example. This is not possible because the long position must already be in place before the strategy can even come into effect.

\section{Actual Examples Of The Correlated Protective Put Strategy}

\section{Example of Small Change in the Long Investment Price}

An investor purchases 100 shares of Intel stock on January 2, 2003, at $\$ 16.63$ per share for a total price of $\$ 1,663.00$. $^{6}$ The investor perceives a selling opportunity on October 28,2003 , at $\$ 32.65$ per share for a total price of $\$ 3,265.00$, with a potential profit of $\$ 1,602.00$. Since the holding period would only be 299 days, if the stock is sold, the profit from the sale would be taxed at the ordinary income tax rate for that investor. The tax incurred would be $\$ 160.20, \$ 240.30, \$ 400.50, \$ 448.56, \$ 528.66$, and $\$ 560.70$ for the $10 \%, 15 \%, 25 \%, 28 \%$, 33\% , and $35 \%$ tax brackets, respectively. If an investor in the higher tax brackets sells with a one-year or less holding period, he/she can lose a large portion of his/her gain due to taxes. Yet, if he/she holds the investment for the required greater than one-year holding period to qualify for the lower long-term capital gains tax rate, he/she has the chance of losing paper gains from stock price fluctuations. The investor cannot hedge with a protective put on Intel because the IRS will reset the holding period to zero when the Intel put is purchased. However, if he/she purchases a put option on a different investment that is highly correlated to Intel, he/she would qualify for the long-term capital gains tax rate on the Intel investment and in turn, protect to, some degree, the paper gain on Intel, if the price falls. The key to CPPS is to find an investment that has a high correlation to Intel and also has put options available. The selection for this example is Advanced Micro Devices (AMD). Calculations for return correlation between Intel and Advanced Micro Devices are shown in Table 3.

\section{Table 3: Correlation of Advanced Micro Devices and Intel}

\begin{tabular}{|c|c|c|c|}
\hline \multicolumn{4}{|c|}{ Daily Correlation } \\
\hline & 6-months & 1 -year & 3-year \\
\hline Correlation & 0.606903 & 0.628143 & 0.646982 \\
\hline \multicolumn{4}{|c|}{ Weekly Correlation } \\
\hline & 6-months & 1-year & 3-year \\
\hline Correlation & 0.657002 & 0.713185 & 0.671918 \\
\hline
\end{tabular}

The weekly correlations are stronger than the daily correlations and the strongest correlation exists for the one-year assessment period. The weekly returns analysis reduces the effects of nonsystematic risk. Advanced Micro Devices' put option is used to protect the paper profit on the Intel investment in order to recognize the lower capital gains tax rates in this example. Table 4 shows two portfolios, one utilizing CPPS and one

that does not utilize CPPS selling Intel on October 28, 2003 and investing the proceeds in an interest bearing account.

Utilizing the CPPS, the investor purchases an in-,or at-the-money put option on Advanced Micro Devices with an expiration date on January 16,2004 , with a strike price of $\$ 15.00$, at $\$ 1.50$ per share, for a cost of $\$ 150.00$ plus $\$ 12.00$ commission for a total price of $\$ 162.00{ }^{8}$ The put option is purchased with margin dollars at a $5 \%$ rate of interest until January 5, 2004, at which time the loan is repaid when the underlying position is liquidated. ${ }^{9}$ This is a self-financing strategy that an investor could use when purchasing the put option. ${ }^{10}$ The interest on the margin loan is $\$ 1.50$, for a total cost of $\$ 163.54$ for the put option.

\footnotetext{
${ }^{6}$ Commission costs are not considered for the purchase or sale of the long position in the analyses since they would be incurred regardless of whether this strategy is utilized or not.

${ }^{7} \mathrm{~A}$ correlation of +1 would be a perfectly correlated investment. A Zero correlation would indicate the two investments do not move together and each is random. A -1 correlation indicates the investments move in the opposite direction.

${ }^{8}$ The commission is included here because with the strategy utilizing the CPPS, a commission cost is incurred, but if the strategy is not utilized the commission cost is not incurred.

${ }^{9}$ The margin rate of 5\% is taken from the rates quoted at www.ameritrade.com website on October 26, 2003.

${ }^{10}$ If the investor does not need to use margin capital to purchase the put option, the return (or cost) from the strategy would be greater (lower).
} 
Table 4: Intel and Advance Micro Devices Strategy

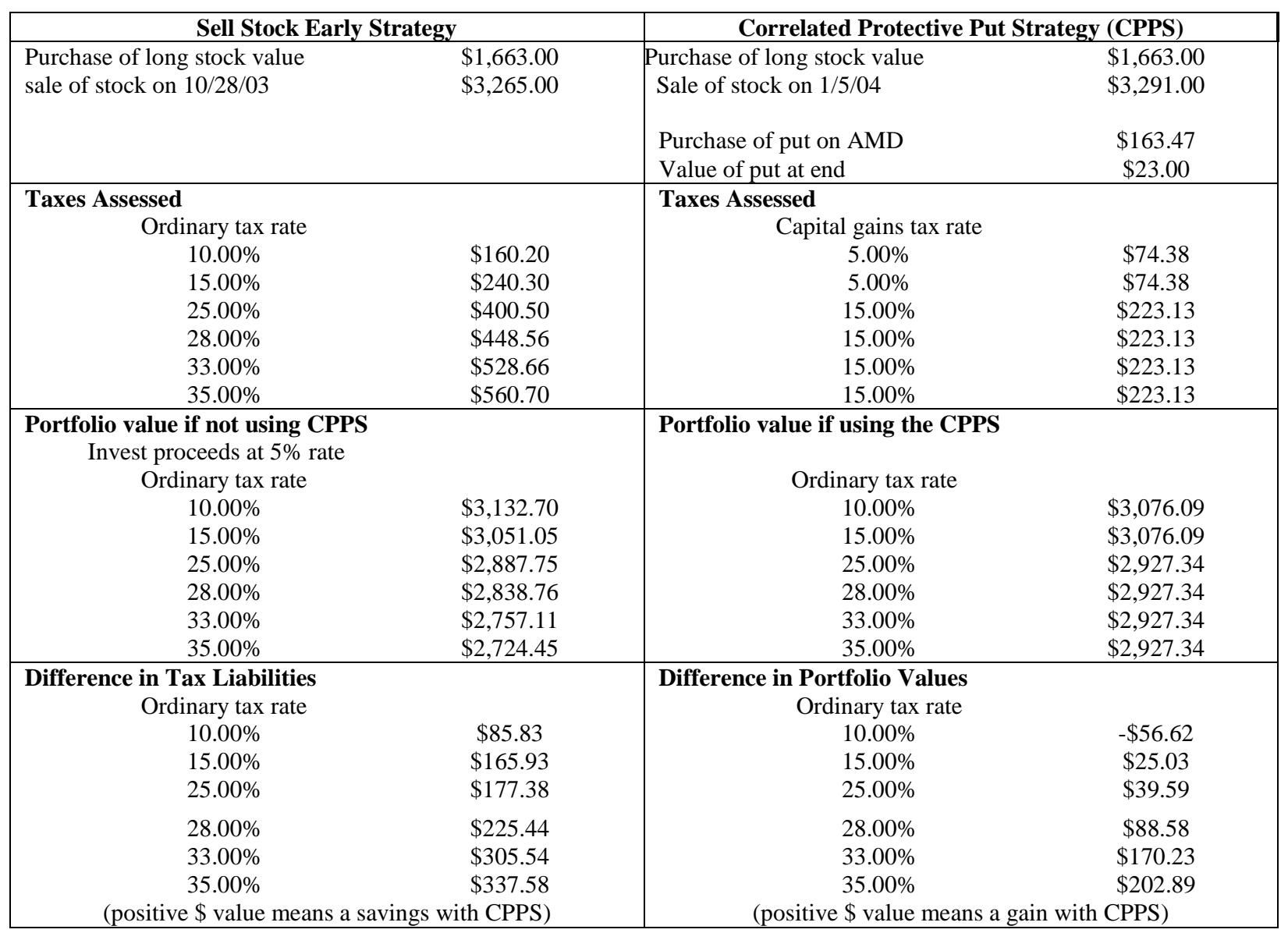

Table 4 shows how the investor fares with this strategy if he/she is in the $10 \%, 15 \%, 25 \%, 28 \%, 33 \%$ or $35 \%$ ordinary income tax bracket. The difference between the after-tax value of the investment portfolio utilizing the CPPS and the after-tax value of the investment portfolio not utilizing the CPPS when the investor sells the stock on October 28, 2003, with the proceeds reinvested in an account earning the margin rate of return is shown above. ${ }^{11}$

As shown in Table 4, the value of Intel on January 5, 2004 is $\$ 32.91$ per share, which is higher than the price of $\$ 32.65$ on October 28,2003 . Thus, the investor experiences an increase in the holding period and a minimal change in price to realize the lower long-term capital gains tax rates. The savings in taxes shown in Table 4 indicate that in all tax brackets the investor saves in total taxes paid, and if the investor is in the highest tax bracket (35\%) he/she saves $\$ 337.58$, which is a $21 \%$ savings on taxes paid on the investment in this example. The difference between the portfolio using the CPPS and the portfolio not using CPPS shows the benefits for the investor using CPPS when he/she is in the $15 \%$ tax bracket or higher. Conversely, if the investor is in the $10 \%$ tax bracket, he/she should have sold Intel on October 28, 2003, and invested the proceeds at 5\% because the difference between his/her ordinary tax rate and long-term capital gains tax rate is $5 \%$, smaller than in the higher tax brackets. As it happens in this case, the correlated protective put still had some value because the price of Intel or Advanced Micro Devices did not significantly move from October 28, 2003 to January 5, 2004. Therefore, the investor is able to sell the put option but still recognizes a loss on the put option investment.

\footnotetext{
${ }^{11}$ If the proceeds are placed in a risk-free investment or a money market account, the return of the deposit would be lower; therefore, making the protective put strategy even more appealing.
} 


\section{Example of an Increase in the Long Investment Price}

An investor is faced with a situation where he/she has a gain in the price of the stock, but the gain is not large enough for the lower long-term capital gains tax rate to offset the entire cost of the put option. The CPPS would still be useful in reducing the effective price of the correlated put option that protects the investor's paper profit while still allowing for upside potential. For example, an investor purchases 100 shares of Ford Motor Company stock on January 2, 2003, at $\$ 9.94$ per share for a total of $\$ 994.00$. The investor perceives an opportunity to sell the stock on October 28,2003 , at $\$ 12.43$ per share for a total of $\$ 1,243.00$, with a potential profit of $\$ 249.00$. Since the holding period would be only 299 days, any profit on the sale of the stock would be taxed at the ordinary income tax rate of the investor. However, the use of the CPPS not only extends the holding period, but also allows for future up-side potential in the Ford long investment position. To examine this strategy, an investor must first find a correlated investment that has put options available. General Motors Corporation is a logical choice, and the correlations are shown in Table 5.

Table 5: Correlation of Ford and General Motors

\begin{tabular}{|l|l|l|l|}
\hline \multicolumn{4}{|l|}{ Daily Correlation } \\
\hline & 6-months & 1-year & 3-year \\
\hline Correlation & 0.673008 & 0.712099 & 0.679193 \\
\hline Weekly Correlation \\
\hline & 6-months & 1-year & 3-year \\
\hline Correlation & 0.790504 & 0.730603 & 0.641029 \\
\hline
\end{tabular}

General Motors has a higher correlation to Ford than Advanced Micro Devices did with Intel (in the previous example) with a correlation between .64 and .79. The CPPS is evaluated in the same manner as in the analysis above. The comparison will analyze whether the investor should sell Ford on October 28, 2003, or use the CPPS by purchasing an in- or at-the-money put option on General Motors to protect the paper profit, and allow for continued upside potential and lower long-term capital gains taxes. Table 6 shows the results of the analysis of the two choices.

Utilizing the CPPS, the investor purchases an in-, or at-the money put option on General Motors with an expiration date on January 16,2004 , a strike price of $\$ 42.50$, a cost of $\$ 2.00$ per share, at a cost of $\$ 200.00$ plus $\$ 12.00$ commission for a total price of $\$ 212.00$. The General Motors put option is purchased with margin dollars at a 5\% interest rate until January 5, 2004, at which time the loan would be repaid when the underlying position is liquidated. The interest on the margin loan is $\$ 2.01$, for a total cost of $\$ 214.01$ for the put option. The correlated protective put would cost more than the gain on the sale of the Ford stock after a one-year holding period for an investor in the $25 \%$ or higher tax bracket. On October 28,2003 , the gain on the Ford stock is $\$ 236$, minus the taxes of $\$ 59.00$ (25\% tax bracket), with a total profit of $\$ 177.00$; the cost of the GM put totals $\$ 214.01$ generating a loss of $\$ 37.01 .^{12}$

The results in Table 6 show the difference between the after-tax value of the Ford investment portfolio utilizing the CPPS and the after-tax value of the investment portfolio without the use of CPPS to extend the holding period and when, instead, the investor just sells the shares on October 28, 2003, and invests the proceeds in an account earning 5\%. The calculation demonstrates that even if the cost of the put originally appears to be more than the stock gain in the $25 \%$ or higher tax brackets, the put maintains upside potential and limits downside risk. Also, notice an investor would actually pay less in taxes in the $25 \%$ and $28 \%$ tax bracket if he/she sold the Ford investment on October 28, 2003. Yet, the CPPS would have allowed an investor to experience an increase in the Ford stock from October 28, 2003 to January 5, 2004 from $\$ 12.30$ to $\$ 16.59$ per share, recognizing a total additional gain of $\$ 429.00$ on the long investment. However, the CPPS reduces this additional gain on the long position by \$214.01, which represents the GM put cost. If the investor did sell on October 28, 2003 and ignored the CPPS opportunity, he/she would have paid a higher capital gains tax than he/she would have paid if the CPPS was used. In short, the CPPS would allow for an increase in the gain on the investment, and decrease the taxes paid on the gain because tax rates are reduced when holding the investment for a period of longer than one-year. For example, an investor in the 33\% tax bracket who used CPPS would pay \$10.23 less in taxes with \$217.39 more in gains, than if he/she would have just sold on October 28, 2003 and invested the proceeds. Notice, all portfolios, regardless of tax

\footnotetext{
${ }^{12}$ This gain is calculated assuming the Ford stock will not change in price from October 28, 2003, to December 5, 2003. The calculation is discussed to demonstrate even if the cost originally appears negative, the upside potential is maintained.
} 
brackets, increased in value using the CPPS, but note, the increases would not have been possible if Ford stock had not increased in value. For example, the portfolio value on January 5, 2004, with the CPPS, had a minimum gain of $\$ 205.53$ and a maximum gain of $\$ 222.35$, a $20.7 \%$ or $22.4 \%$ increase in the portfolio value, respectively.

Table 6: Ford and General Motors Example

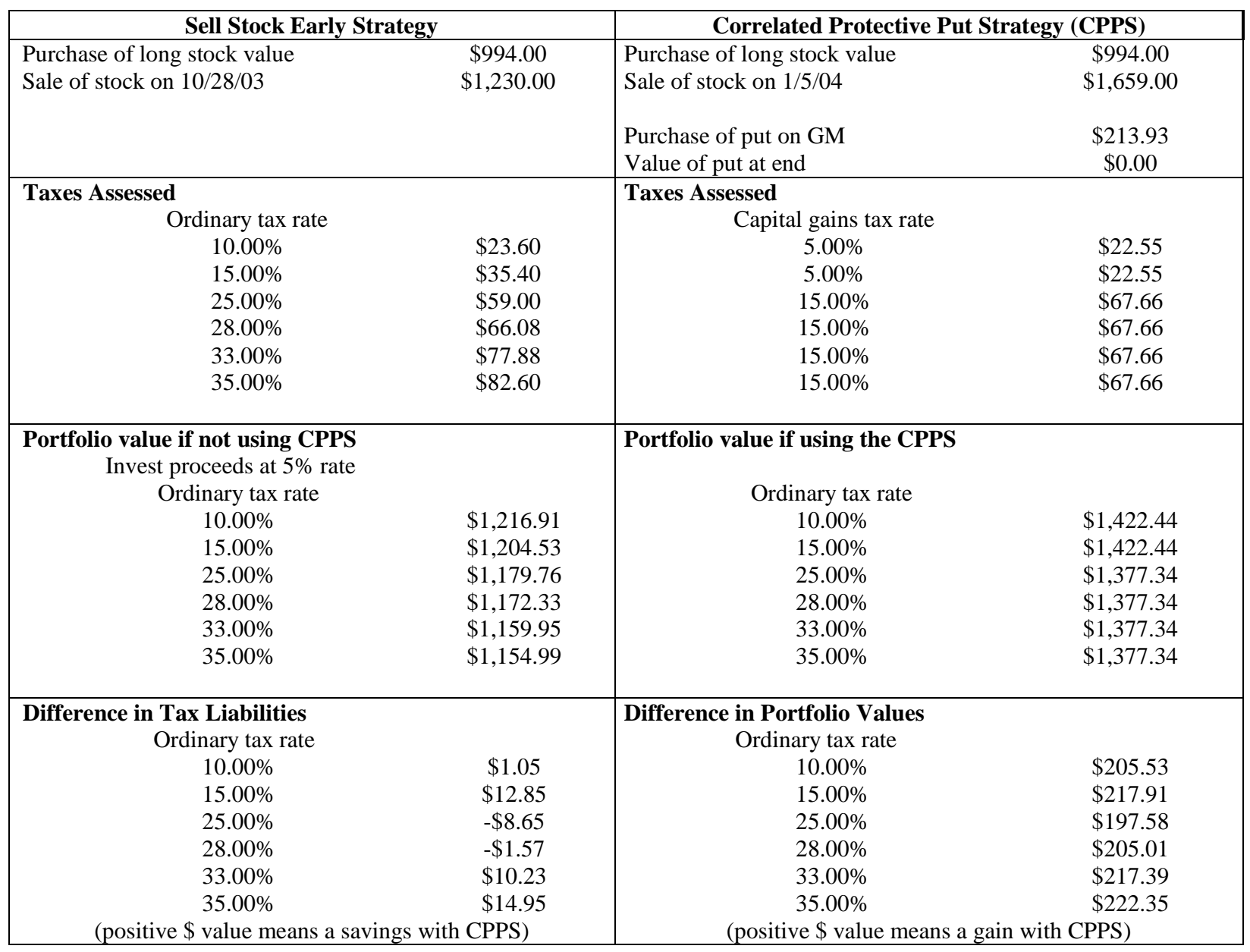

Example of when the Long Position Stock Price Declines

An investor is faced with a situation where he/she has a gain in the price of a stock but has a strong feeling the long position of the stock value will decline before a one-year holding period lapses. The CPPS would be ideal for the investor because the investor's paper profit will be protected while still allowing for upside potential. For example, an investor purchases 100 shares of Target stock on January 2, 2003, at $\$ 30.87$ per share for a total price of $\$ 3,087.00$. The investor perceives a selling opportunity on October 28,2003 , at $\$ 39.62$ per share for a total price of $\$ 3,962.00$, with a potential profit of $\$ 875.00$. Utilizing the CPPS, the investor would identify a company with a high correlation to Target and with put options available. In this example, Wal-Mart will be the correlated company. As shown in Table 7, Wal-Mart has a correlation with Target between .53 and .75. 
Table 7: Correlation of Target and Wal-Mart

\begin{tabular}{|l|l|l|l|}
\hline \multicolumn{4}{|l|}{ Daily Correlation } \\
\hline & 6-months & 1-year & 3-year \\
\hline Correlation & 0.57929 & 0.667759 & 0.695721 \\
\hline Weekly Correlation \\
\hline & 6-months & 1-year & 3-year \\
\hline Correlation & 0.533533 & 0.742338 & 0.745783 \\
\hline
\end{tabular}

The CPPS and early stock selling strategy are evaluated in the same manner as in the other examples. Table 8 shows the results of the two choices, utilizing CPPS or selling on October 28, 2003.

The investor is correct and the price of Target actually dropped from $\$ 39.62$ on October 28,2003 , to $\$ 37.40$ on January 5, 2004, a loss of $\$ 222.00$, and, as expected, the correlated protective put gains in value from $\$ 1,152.37$ to

$\$ 1,768.00$, a gain of $\$ 615.63{ }^{13}$ Thus, in all the ordinary income tax brackets, the taxes assessed are higher in the CPPS situation because the gain on the correlated put is taxed at the short-term ordinary income tax rate, but the remaining gain on the Target stock is now taxed at the lower long-term capital gains tax rates. However, notice that in all tax brackets, the overall CPPS portfolio value is greater than if the investor would have just sold Target on October 28, 2003, and invested the proceeds in an interest bearing account, even with Target's stock value dropping from October 28, 2003, to January 5, 2004. For example, a minimum gain of $\$ 325.95$ is realized for the $25 \%$ tax bracket and a maximum gain of $\$ 353.30$ is realized for the $35 \%$ tax bracket, a $10.6 \%$ and $11.4 \%$ increase in value on the portfolio values, respectively.

Table 8: Target and Wal-Mart Example

\begin{tabular}{|c|c|c|c|}
\hline \multicolumn{2}{|c|}{ Sell Stock Early Strategy } & \multicolumn{2}{|c|}{ Correlated Protective Put Strategy (CPPS) } \\
\hline Purchase of long stock value & $\$ 3,087.00$ & Purchase of long stock value & $\$ 3,087.00$ \\
\hline \multirow[t]{3}{*}{ Sale of stock on $10 / 28 / 03$} & $\$ 3,962.00$ & Sale of stock on $1 / 5 / 04$ & $\$ 3,740.00$ \\
\hline & & Purchase of put on Wal-Mart & $\$ 1,152.37$ \\
\hline & & Value of put at end & $\$ 1,768.00$ \\
\hline \multirow{2}{*}{\multicolumn{2}{|c|}{$\begin{array}{l}\text { Taxes Assessed } \\
\text { Ordinary tax rate }\end{array}$}} & \multicolumn{2}{|l|}{ Taxes Assessed } \\
\hline & & \multicolumn{2}{|l|}{ Capital gains tax rate } \\
\hline $10.00 \%$ & $\$ 87.50$ & $5.00 \%$ & $\$ 96.61$ \\
\hline $15.00 \%$ & $\$ 131.25$ & $5.00 \%$ & $\$ 128.59$ \\
\hline $25.00 \%$ & $\$ 218.75$ & $15.00 \%$ & $\$ 257.86$ \\
\hline $28.00 \%$ & $\$ 245.00$ & $15.00 \%$ & $\$ 277.05$ \\
\hline $33.00 \%$ & $\$ 288.75$ & $15.00 \%$ & $\$ 309.03$ \\
\hline $35.00 \%$ & $\$ 306.25$ & $15.00 \%$ & $\$ 321.82$ \\
\hline \multicolumn{2}{|c|}{ Portfolio value if not using CPPS } & \multicolumn{2}{|l|}{ Portfolio value if using the CPPS } \\
\hline Ordinary tax rate & & \multicolumn{2}{|l|}{ Ordinary tax rate } \\
\hline $10.00 \%$ & $\$ 3,908.36$ & $10.00 \%$ & $\$ 4,258.59$ \\
\hline $15.00 \%$ & $\$ 3,862.73$ & $15.00 \%$ & $\$ 4,226.63$ \\
\hline $25.00 \%$ & $\$ 3,771.47$ & $25.00 \%$ & $\$ 4,097.42$ \\
\hline $28.00 \%$ & $\$ 3,744.09$ & $28.00 \%$ & $\$ 4,078.24$ \\
\hline $33.00 \%$ & $\$ 3,698.46$ & $33.00 \%$ & $\$ 4,046.28$ \\
\hline $35.00 \%$ & $\$ 3,680.21$ & $35.00 \%$ & $\$ 4,033.50$ \\
\hline \multicolumn{2}{|l|}{$\begin{array}{c}\text { Difference in Tax Liabilities } \\
\text { Ordinary tax rate }\end{array}$} & \multicolumn{2}{|l|}{$\begin{array}{c}\text { Difference in Portfolio Values } \\
\text { Ordinary tax rate }\end{array}$} \\
\hline $10.00 \%$ & $-\$ 9.07$ & $10.00 \%$ & $\$ 350.23$ \\
\hline $15.00 \%$ & $\$ 2.73$ & $15.00 \%$ & $\$ 363.90$ \\
\hline $25.00 \%$ & $-\$ 38.99$ & $25.00 \%$ & $\$ 325.95$ \\
\hline $28.00 \%$ & $-\$ 31.91$ & $28.00 \%$ & $\$ 334.15$ \\
\hline $33.00 \%$ & $-\$ 20.12$ & $33.00 \%$ & $\$ 347.83$ \\
\hline $35.00 \%$ & $-\$ 15.40$ & $35.00 \%$ & $\$ 353.30$ \\
\hline \multicolumn{2}{|c|}{ (positive \$ value means a savings with CPPS) } & \multicolumn{2}{|c|}{ (positive \$ value means a gain with CPPS) } \\
\hline
\end{tabular}

\footnotetext{
${ }^{13}$ The gain of $\$ 615.63$ is after taking into account the interest on loan for the purchase of the put option and the commission cost for the purchase and sale of the put option.
} 


\section{Example of when the Long Position Stock Price Declines and Results in a Loss}

In the following example an investor faces a situation where he/she has a small gain in the price of a stock and has held the stock for almost one-year, but has a strong feeling that the long position of the stock value will decline. The CPPS would benefit the investor because the investor's paper profit will be protected, lowering the cost of "insurance", while still allowing for upside potential. For example, an investor purchases 100 shares of Key Corporation stock on June 27,2002 , at $\$ 25.31$ per share for a total price of $\$ 2,531.00$. The investor perceives a selling opportunity on June 12,2003 , at $\$ 26.08$ per share for a total price of $\$ 2,608.00$, with a potential profit of $\$ 77.00$. Utilizing the CPPS, the investor will identify a company with a high correlation to Key Corporation and with put options available. In this example, Bank One will be the correlated company. Bank One has a correlation with Key Corporation between .48 and .73 as shown in Table 9.

Table 9: Correlation of Key Corporation and Bank One

\begin{tabular}{|l|l|l|l|}
\hline \multicolumn{4}{|c|}{ Daily Correlation } \\
\hline & 6-months & 1-year & 3-year \\
\hline Correlation & 0.641309 & 0.731404 & 0.679929 \\
\hline Weekly Correlation \\
\hline & 6-months & 1-year & 3-year \\
\hline Correlation & 0.475953 & 0.616876 & 0.580314 \\
\hline
\end{tabular}

The CPPS and early stock selling strategy are evaluated in the same manner as in the other examples. Table 10 shows the results of the two choices, utilizing CPPS or selling Key Corporation on June 12, 2003.

The investor is correct and the price of Key Corporation actually dropped from $\$ 26.08$ on June 12 , 2003 , to $\$ 24.71$ on June 30,2003 , for a loss of $\$ 137.00$ eliminating the entire gain on the long investment position, and, as expected, the correlated protective put gains in value from $\$ 148.33$ to $\$ 273.00$, a gain of $\$ 124.67 .{ }^{14}$ From June 12, 2003 to June 30, 2003, the investor has a paper loss on the CPPS portfolio of $\$ 12.33$. In all the ordinary income tax brackets, the taxes assessed are lower in the CPPS situation because the gain on the correlated put is $\$ 124.67$ less the $\$ 60.00$ loss on the long position, which nets a CPPS portfolio gain of $\$ 64.67$ which is less than the $\$ 77.00$ gain if the investor had sold on June 12, 2003. Both portfolio gains are taxed at the short-term ordinary tax rate. In this example comparing portfolio values, the investor would have been better off selling the Key Corporation investment on June 12, 2003 before the decline in the stock value.

However, if the investor wanted to recognize the lower capital gains tax rates and figured he/she could just wait out the remaining 18 days, he/she would have suffered a loss of $\$ 60.00$ on the Key Corporation long investment. Utilizing the CPPS, the investor's portfolio would have a gain of $\$ 64.67$. Table 11 shows the net effect after-tax considerations if the investor attempted to wait out the 18 days by holding the stock versus utilizing the CPPS to recognize the lower long-term capital gains tax rates

The $\$ 60.00$ loss could be used to offset other capital gains, or offset ordinary income up to a maximum of $\$ 3,000$ of losses per year (Code Sec. 1211), losses in excess of $\$ 3,000.00$ can be carried forward (Code Sec. 1754), thus resulting in a lower net after-tax loss. The investor would thus incur a net loss of $\$ 39.00$ to $\$ 54.00$. The CPPS would result in a net short-term gain of $\$ 64.67$, causing the investor to pay a portion of the gain in taxes. The net after-tax gain on the portfolio ranges from $\$ 42.04$ to $\$ 58.20$. The $\$ 64.67$ gain is the result of the $\$ 124.67$ gain in the correlated protective put purchased on Bank One less the loss of the $\$ 60.00$ on the Key Corporation investment. Thus, if the investor held the shares for the remaining 18 days in an attempt to recognize the lower long-term capital gains tax rates, the net difference in the portfolio value between holding the stock and utilizing the CPPS is between $\$ 81.04$ and \$112.20. However, if the investor sold the Key Corporation investment on June 12, 2003, he/she would have been better off not utilizing the CPPS and ending up with a higher portfolio value.

\footnotetext{
${ }^{14}$ The gain of $\$ 124.67$ is after taking into account the interest on the loan for the purchase of the put option and the commission cost for the purchase and sale of the put option.
} 
Table 10: Key Corporation and Bank One Example

\begin{tabular}{|c|c|c|c|}
\hline \multicolumn{2}{|c|}{ Sell Stock Early Strategy } & \multicolumn{2}{|c|}{ Correlated Protective Put Strategy (CPPS) } \\
\hline Purchase of long stock value & $\$ 2,531.00$ & Purchase of long stock value & $\$ 2,531.00$ \\
\hline \multirow[t]{3}{*}{ Sale of stock on $6 / 12 / 03$} & $\$ 2,608.00$ & Sale of stock on $6 / 30 / 03$ & $\$ 2,471.00$ \\
\hline & & Purchase of put on Bank One & $\$ 148.33$ \\
\hline & & Value of put at end & $\$ 273.00$ \\
\hline Taxes Assessed & & Taxes Assessed & \\
\hline Ordinary tax rate & & Capital gains tax rate & \\
\hline $10.00 \%$ & $\$ 7.70$ & $5.00 \%$ & $\$ 11.87$ \\
\hline $15.00 \%$ & $\$ 11.55$ & $5.00 \%$ & $\$ 19.30$ \\
\hline $25.00 \%$ & $\$ 19.25$ & $15.00 \%$ & $\$ 28.17$ \\
\hline $28.00 \%$ & $\$ 21.56$ & $15.00 \%$ & $\$ 32.63$ \\
\hline $33.00 \%$ & $\$ 25.41$ & $15.00 \%$ & $\$ 40.06$ \\
\hline $35.00 \%$ & $\$ 26.95$ & $15.00 \%$ & $\$ 43.03$ \\
\hline \multicolumn{2}{|c|}{ Portfolio value if not using CPPS } & \multicolumn{2}{|l|}{ Portfolio value if using the CPPS } \\
\hline Ordinary tax rate & & \multicolumn{2}{|l|}{ Ordinary tax rate } \\
\hline $10.00 \%$ & $\$ 2,606.09$ & $10.00 \%$ & $\$ 2,583.80$ \\
\hline $15.00 \%$ & $\$ 2,601.92$ & $15.00 \%$ & $\$ 2,576.37$ \\
\hline $25.00 \%$ & $\$ 2,593.58$ & $25.00 \%$ & $\$ 2,567.50$ \\
\hline $28.00 \%$ & $\$ 2,591.08$ & $28.00 \%$ & $\$ 2,563.04$ \\
\hline $33.00 \%$ & $\$ 2,586.90$ & $33.00 \%$ & $\$ 2,555.61$ \\
\hline $35.00 \%$ & $\$ 2,585.23$ & $35.00 \%$ & $\$ 2,552.63$ \\
\hline \multicolumn{2}{|l|}{ Difference in Tax Liabilities } & \multicolumn{2}{|l|}{ Difference in Portfolio Values } \\
\hline \multicolumn{2}{|l|}{ Ordinary tax rate } & \multicolumn{2}{|l|}{ Ordinary tax rate } \\
\hline $10.00 \%$ & $\$ 3.27$ & $10.00 \%$ & $-\$ 14.86$ \\
\hline $15.00 \%$ & $\$ 7.12$ & $15.00 \%$ & $-\$ 10.69$ \\
\hline $25.00 \%$ & $\$ 5.95$ & $25.00 \%$ & $-\$ 11.21$ \\
\hline $28.00 \%$ & $\$ 8.26$ & $28.00 \%$ & $-\$ 8.71$ \\
\hline $33.00 \%$ & $\$ 12.11$ & $33.00 \%$ & $-\$ 4.54$ \\
\hline $35.00 \%$ & $\$ 13.65$ & $35.00 \%$ & $-\$ 2.87$ \\
\hline \multicolumn{2}{|c|}{ (positive $\$$ value means a savings with CPPS) } & \multicolumn{2}{|c|}{ (positive $\$$ value means a gain with CPPS) } \\
\hline
\end{tabular}

Table 11: Portfolio Result if an Investor Chooses to Wait for the Lower Long-Term Capital Gain Tax Rates

\begin{tabular}{|l|c|c|c|c|c|}
\hline Tax rate & $\begin{array}{c}\text { Loss if not } \\
\text { utilizing CPPS }\end{array}$ & $\begin{array}{c}\text { Net tax effect of } \\
\text { not utilizing CPPS }\end{array}$ & $\begin{array}{c}\text { Gain if Utilizing } \\
\text { CPPS }\end{array}$ & $\begin{array}{c}\text { Net effect } \\
\text { of utilizing CPPS }\end{array}$ & $\begin{array}{c}\text { Difference } \\
\text { between choices }\end{array}$ \\
\hline $10.00 \%$ & $-\$ 60.00$ & $-\$ 54.00$ & $\$ 64.67$ & $\$ 58.20$ & $\$ 112.20$ \\
\hline $15.00 \%$ & $-\$ 60.00$ & $-\$ 51.00$ & $\$ 64.67$ & $\$ 54.97$ & $\$ 105.97$ \\
\hline $25.00 \%$ & $-\$ 60.00$ & $-\$ 45.00$ & $\$ 64.67$ & $\$ 48.50$ & $\$ 93.50$ \\
\hline $28.00 \%$ & $-\$ 60.00$ & $-\$ 43.20$ & $\$ 64.67$ & $\$ 46.56$ & $\$ 89.76$ \\
\hline $33.00 \%$ & $-\$ 60.00$ & $-\$ 40.20$ & $\$ 64.67$ & $\$ 43.33$ & $\$ 83.53$ \\
\hline $35.00 \%$ & $-\$ 60.00$ & $-\$ 39.00$ & $\$ 64.67$ & $\$ 42.04$ & $\$ 81.04$ \\
\hline
\end{tabular}

\section{Caveats}

This CPPS works well when the two investments are highly correlated, but past correlation does not guarantee two investments will continue to be highly correlated in the future. Thus, a loss can result from employing the CPPS, and the investor should understand the risks associated with any investment or investment strategy before committing capital. Another limitation is a lack of highly correlated put option choices to confidently protect paper profit using the CPPS. 


\section{Summary}

The correlated protective put strategy (CPPS) is a hedging strategy not disallowed by the IRS. Simply, the strategy lengthens the holding period of the investment to greater than one-year to allow the investor to recognize a lower long-term capital gains tax rate. The CPPS can be used when the investor has a paper profit on an investment while holding the investment for less than one-year. The investor identifies a highly correlated investment with put options available in the marketplace. The purchase of the highly correlated put creates a modified protective put insurance hedge. The CPPS has three main advantages in addition to the extension of the holding period (tax consequences): (1) protects the paper profit, (2) allows for upside potential on the investment, and (3) limits downside risk.

The analysis conducted in this paper compares the value of an investor's portfolio if he/she had sold the investment after holding the investment for less than one-year and invests the proceeds in an interest bearing account to a portfolio using CPPS to extend the holding period to longer than one-year and realize the benefits the lower long-term capital gains tax rate. Of the four scenarios analyzed above, the majority concluded that an investor who applied CPPS had a larger after-tax portfolio following a one-year holding period than an investor who did not use the strategy. While the benefits of the CPPS may not be available in every investment situation or tax bracket, the strategy is worthy of consideration for any tax conscious individual.

Notes 
Notes 